\title{
PENGEMBANGAN MODEL PASSING ATAS BOLAVOLI UNTUK USIA SMP
}

\author{
Valentino Hary \\ Universitas Nahdlatul Ulama Blitar \\ haryvalentino@gmail.com
}

\begin{tabular}{l}
\hline Tersedia Online di \\
\hline http://www.jurnal.unublitar.ac.id/ \\
index.php/briliant \\
\hline
\end{tabular}

\begin{tabular}{l}
\hline Sejarah Artikel \\
\hline Diterima pada 28 Januari 2019 \\
Disetuji pada 11 Februari 2019 \\
Dipublikasikan pada 20 Februari \\
2019 Hal. 63-71
\end{tabular}

\begin{tabular}{l}
\hline Kata Kunci: \\
analisis kebutuhan, model passing \\
atas bolavoli, efektifitas. \\
\hline
\end{tabular}

DOI:

http://dx.doi.org/10.28926/briliant .v3i3.270

\begin{abstract}
Abstrak: Secara umum tujuan dari penelitian dan pengembangan ini adalah untuk menghasilkan model passing atas bolavoli untuk usia SMP. Selain itu, penelitian dan pengembangan ini dilakukan untuk memperoleh informasi secara mendalam tentang: pengembangan dan penerapan model passing atas bolavoli untuk usia SMP dan mengetahui efektivitas, efisiensi dan daya tarik hasil pengembangan model passing atas bolavoli untuk usia SMP. Penelitian dan pengembangan ini menggunakan pendekatan kualitatif serta menggunakan metode Penelitian Pengembangan Research \& Development (R \& D). Instrumen yang digunakan dalam penelitian dan pengembangan ini adalah angket, kuisioner yang digunakan untuk mengumpulkan data pada tahap: (1) analisis kebutuhan; (2) evaluasi ahli (evaluasi produk awal); (3) ujioba terbatas (ujicoba kelompok kecil); dan (4) ujicoba utama (field testing). Efektivitas penerapan model passing atas bolavoli pada siswa ini digunakan teknik "ujit". Sebelum data dianalisis, dilakukan uji normalitas terhadap data hasil pretest dan posttest passing atas bolavoli dengan menggunakan uji Lilliefors pada taraf
\end{abstract} nyata $\alpha=0,05$. Hasil passing atas bolavoli antara pretest dengan posttest diperoleh nilai $t_{\mathrm{O}}=4,512$ lebih besar dari nilai $\mathrm{t}_{\mathrm{t}}=1,796$ maka hipotesis nihil ditolak serta nilai rata-rata pretest $\left(\mathrm{x}_{1}\right)=12.67$ lebih kecil daripada rata-rata posttest $\left(\mathrm{x}_{2}\right)=13.92$. Berdasarkan hasil pengembangan dapat disimpulkan bahwa: (1) Dengan model passing atas bolavoli untuk usia SMP, anak dapat belajar secara efektif dan efisien.(2) Dengan model yang telah peneliti kembangkan, anak lebih termotivasi serta aktif dalam mengikuti proses belajar passing atas..

\section{PENDAHULUAN}

Bolavoli merupakan salah satu cabang olahraga yang populer dikalangan masyarakat Indonesia dari kalangan bawah hingga atas olahraga. Bolavoli merupakan suatu permainan yang kompleks yang tidak mudah dilakukan oleh setiap orang, sebab dalam permainan bolavoli dibutuhkan koordinasi gerak yang benar-benar bisa diandalkan untuk melakukan semua gerakan yang ada dalam permainan bolavoli" (Ahmadi, 2007:20). Meskipun begitu hal tersebut tidak menghalangi masyarakat untuk mempelajari lebih mendalam karena ketertarikan yang terjadi di masyarakat tinggi.

Kelebihan lain dari bolavoli diungkapkan juga oleh Papageorgiou (2002:11) yang menyatakan "Volleyball is a game that is suitable for both sexes and for players of all ages and abilities and can be adapted to allow players with a physical or mental disability to play at competitive level". Permainan yang dapat dimainkan oleh laki-laki maupun perempuan bahkan untuk orang berkebutuhan khusus tentunya dengan disesuaikan tingkat kesulitannya dalam 
berkompetisi. Barbara L Viera dan Bonnie Jill Ferguson (2010: 49) menyatakan kelebihan-kelebihan lain dari permainan bolavoli antara lain:

(1) It is adaptable to various conditions that may present themselves, (2) It can be played with any number on a side from two, which is extremely popular in the beach game, to six. which is the number used for interscholastic, intercollegiate, junior, and club play, (3) It can be played and enjoyed by all ages and ability levels, (4) It can be played on many surfaces-grass, wood, sand, and various artificial surfaces, (5) It is an excellent co-ed activity, (6) It is an exciting spectator sport, (7) It can be played indoors or outdoors, (8) It is an extremely popular recreational activity with numerous leagues in business,community, and school intramural programs, (9)It requires few basic rules and skills, and (10) It has limited equipment needs."

Viera dan Fergusson (2000:1) menyatakan bahwa "permainan ini cepat menarik perhatian karena hanya membutuhkan sedikit keterampilan dasar, mudah dikuasai dalam jangka waktu latihan yang singkat dan dapat dilakukan oleh pemain dengan berbagai tingkat kebugaran." Bahkan kita bisa menemui permainan bolavoli di lakukan antar desa atau yang dikenal dengan gala desa yang membuat permainan bolavoli begitu populer di kalangan masyarakat. Menurut Atmasubrata (2012:50) bolavoli adalah "olahraga permainan yang dimainkan oleh dua grup berlawanan. Masing-masing grup memiliki enam orang pemain dan terdapat pula variasi permainan bolavoli pantai yang masing-masing grup hanya memiliki dua orang pemain."

Permainan bolavoli yang telah ditetapkan secara jelas mengenai sarana dan prasarananya masih bisa diubah secara fleksibel dengan melihat situasi dan kondisi yang ada di sekitar masyarakat. Maka berdasarkan penjelasan teori-teori di atas maka bolavoli merupakan permainan beregu yang dimainkan oleh 6 orang masing-masing regu dengan cara bermain memasukkan bola ke daerah lawan dengan melewati net sebagai rintangan dan berusaha untuk memenangkan permainan dengan cara mematikan bola dengan cara atau teknik tertentu.

Teknik dasar yang terdapat dalam permainan bolavoli menurut Ahmadi (2007:20) menyebutkan bahwa "teknik-teknik dalam permainan bolavoli terdiri atas servis, passing bawah dan passing atas,block, dan smash." Teknik-teknik dasar yang terdapat dalam permainan bolavoli sangat mempengaruhi keterampilan seseorang dalam permainan bolavoli. Berdasarkan hasil observasi analisis kebutuhan yang dilakukan ditemukan bahwasanya siswa salah satu SMP (Sekolah Menengah Pertama) di Probolinggo kurang termotivasi dalam mengikuti materi passing atas bolavoli. Sehingga dari hasil observasi di atas guru dan siswa membutuhkan model passing atas bolavoli yang baru sehingga selain dapat memotivasi siswa juga dapat menambah kualitas teknik passing atas. Berdasarkan latar belakang di atas, peneliti ingin mengembangkan model-model passing atas bolavoli. Untuk itu, peneliti akan mengadakan pengembangan model passing atas bolavoli untuk usia SMP (Sekolah Menengah Pertama). 


\section{Kajian Teoretik}

\section{Konsep Pengembangan Model}

Metode penelitian pada dasarnya merupakan cara ilmiah untuk mendapatkan data untuk mencapai tujuan tertentu dan memperoleh kegunaan tertentu. Dalam dunia pendidikan, penelitian memiliki tujuan untuk memecahkan masalah yang terjadi dengan menjawab secara ilmiah, Punaji Setyosari (2013:16) menyebutkan "penelitian merupakan suatu cara yang tepat dan sangat berguna dalam memperoleh informasi yang sahih dan dapat dipertanggungjawabkan." Salah satu metode penelitian yang relevan dan dapat selalu digunakan yaitu penelitian pengembangan atau Research and Development $(R \& D)$. Winarno (2011:76) menjelaskan bahwa "penelitian pengembangan merupakan penelitian yang berupaya mengembangkan produk tertentu sesuai dengan kebutuhan masyarakat saat ini."

Penelitian dan pengembangan saat ini banyak digunakan untuk memecahkan masalah pada dunia pendidikan, maka penelitian ini diharapkan mampu membantu seorang guru untuk memecahkan permasalahan. Seperti yang di ungkapkan oleh Conny Semiawan (2007:181) yang menyebutkan "penelitian dan pengembangan merupakan perbatasan dari pendekatan kualitatif dan kuantitatif terutama untuk menjembatani kesenjangan antara penelitian dan praktik pendidikan." Berfungsi sebagai jembatan tentunya seorang guru menjadi jalur pengarah peserta didik hingga mencapai "ujung jembatan" yakni tujuan pendidikan. Selain itu Sugiyono (2013:297) menyebutkan bahwa "penelitian dan pengembangan adalah penelitian yang digunakan untuk menghasilkan produk tertentu, dan menguji keefektifan produk tersebut." Hasil produk tersebut bisa dari hasil pengembangan produk lama yang dikembangkan lagi ataupun produk yang baru. Sukmadinata (2012:164) menyatakan bahwa "penelitian dan pengembangan adalah suatu proses atau langkah-langkah untuk mengembangkan suatu produk baru atau menyempurnakan produk yang sudah ada yang dapat dipertanggungjawabkan."

Pada pendidikan pengembangan memfokuskan pada kajiiannya pada bidang desain atau rancangan apakah itu model, dan desain bahan ajar, produk misalnya media dan juga proses. Contoh pengembangan dari bahan pengajaran adalah buku ajar, alat peraga, modul dan lain sebagainya. Berdasarkan hal tersebut maka penelitian dan pengembangan merupakan penelitian yang dilakukan berdasarkan analisis kebutuhan lapangan, yang nantinya akan digunakan sebagai landasan penyusunan draft pengembangan dan akan menghasilkan suatu produk pengembangan baru atau penyempurnaan produk yang telah ada.

\section{Konsep Model Yang Dikembangkan}

Pendidikan jasmani merupakan pendidikan yang dilakukan melalui aktivitas fisik sebagai "jembatan" untuk mencapai tujuan. Untuk mencapai tujuan tersebut tentunya diperlukan adanya inovasi model. Pengembangan model merupakan salah satu bentuk dari penerapan pendekatan sistem dalam kegiatan pembelajaran yang notabene telaah suatu proses sistematis yang menghasilkan suatu sistem pembelajaran yang siap untuk digunakan dengan tepat seperti dengan pengembangan model.

Hasil dari pengembangan model harus dilakukan secara bertahap, menyeluruh dan komprehensif dengan tujuan untuk meningkatkan kompetensi belajar siswa. 
Sugiyono (2013:297) menyatakan, "untuk menghasilkan produk tertentu digunakan penelitian yang bersifat analisis kebutuhan dan untuk menguji keefektifan produk tersebut supaya dapat berfungsi di masyarakat luas." Analisis kebutuhan ini berlaku dalam menetapkan model yang akan dikembangkan dalam penelitian ini agar hasilnya sesuai dengan yang dibutuhkan oleh siswa dalam proses belajar.

\section{Kerangka Teoretik \\ Karakteristik Anak SMP}

Karakteristik peserta didik sekolah menengah pertama berkisar antara 14-15 tahun. Perkembangan pada masa ini termasuk dalam masa adolesensi. Sugiyanto et al (2007:176) menyebutkan "Masa adolesensi merupakan masa transisi dari masa kanak-kanak menuju masa dewasa." Pada masa ini terjadi pertumbuhan yang sangat pesat meskipun pertumbuhan anak laki-laki lebih lambat dibandingkan dengan anak perempuan. Anak perempuan terjadi pada kisaran usia 8,5 hingga 11,5 tahun dengan puncak rata-rata pada 12,5 tahun, sedangkan untuk anak laki-laki terjadi pada usia 10,5 hingga 14,5 dan mencapai puncak rata-rata pada 14,5 hingga 15,5 tahun.

Berikut ini merupakan masa puber yang terjadi pada anak laki-laki dan perempuan:

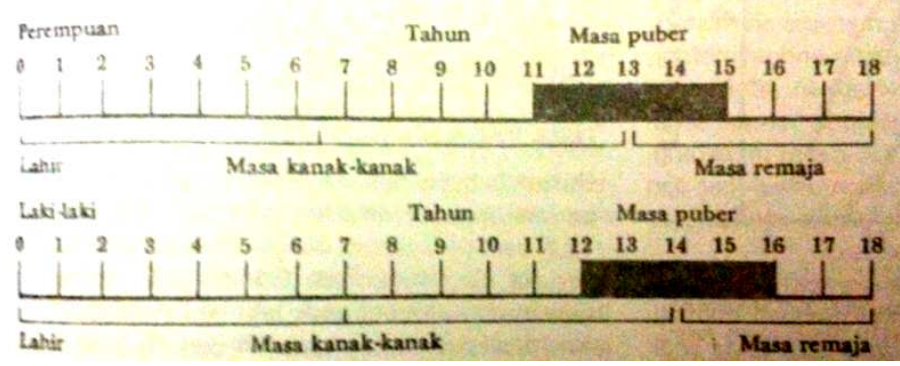

Sumber: Elizabeth B. Hurlock. Psikologi Perkembangan Suatu Pendekatan Sepanjang Rentang Kehidupan terjemahan Istiwidayanti dan Soedjarwo, (Jakarta: Erlangga, 2002), h. 185.

Berdasarkan gambar tersebut terlihat bahwa terdapat perbedaan masa puber yang terjadi pada anak laki-laki dengan anak perempuan. Dimana masa kanakkanak untuk perempuan hanya berlangsung hingga usia 11 tahun dan mengalami masa puber pada kisaran usia 11 hingga 15 tahun. Sedangkan anak laki-laki masa kanak-kanak terjadi hingga usia 12 tahun dan baru mengalami masa puber pada kisaran usia 12 hingga 16 tahun.

\section{Passing Atas Bolavoli}

Salah satu teknik dasar dalam permainan bolavoli adalah passing . Subroto dan Yudiana (2010:47) menyatakan bahwa "passing dalam permainan bolavoli adalah istilah cara memainkan bola pertama setelah bola berada dalam permainan akibat serangan lawan, servis lawan, atau permainan net (cover spike dan cover block). Jenis-jenis passing ada dua yaitu passing atas dan passing bawah. Dalam passing atas terdapat tahapan-tahapan yang harus diketahui, tahapan tersebut yakni sikap permulaan, sikap pelaksanaan dan sikap akhir. 

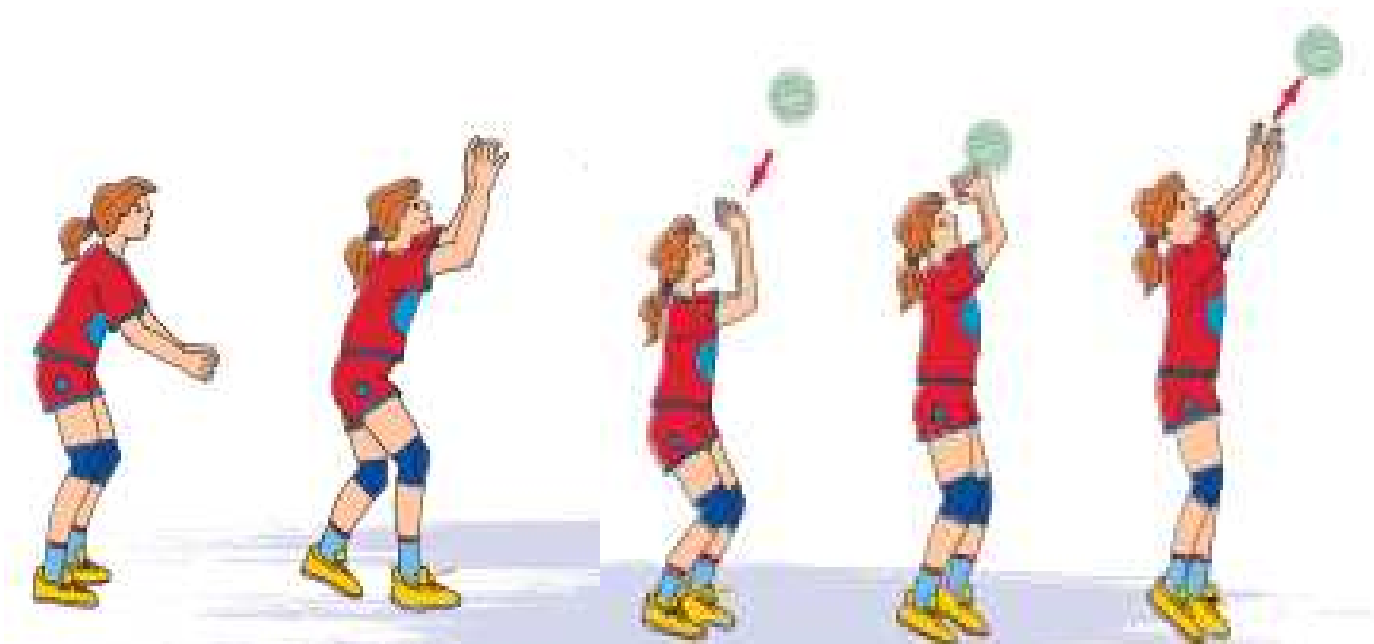

Gambar 2. Tahapan Passing Atas: Overhead Pass Start, Movement To The Ball And Contact, And Follow-Through. Sumber: Barth Katrin \& Richard Heuchert., Learning Volleyball (Germany:Meyer and Meyer Sport, 2007), hh 67-69.

\section{a. Sikap Persiapan}

Pada teknik dasar passing khususnya passing atas memiliki sikap persiapan, sedangkan sikap siap normal dalam bermain voli adalah pengambilan sikap tubuh sedemikian hingga memudahkan untuk secepatnya bergerak ke arah yang diinginkan.

Berdasarkan hal tersebut dapat dipaparkan bahwa secara keseluruhan tubuh harus dalam keadaan seimbang agar dapat berkoordinasi sehingga dapat berpindah-pindah ke arah yang diinginkan dalam waktu yang sesingkat mungkin. Sikap normal ketika akan melakukan passing atas yakni berdiri dengan salah satu kaki berada di depan, lutut agak ditekuk agak condong sedikit ke depan dengan tangan berada di depan dada, saat akan passing atas dengan menempatkan diri di bawah bola dan kedua tangan diangkat ke atas depan kira-kira setinggi dahi, jarijari tangan membentuk suatu bulatan, jari-jari direnggangkan sedikit satu dengan yang lain dan kedua ibu jari membentuk sudut.

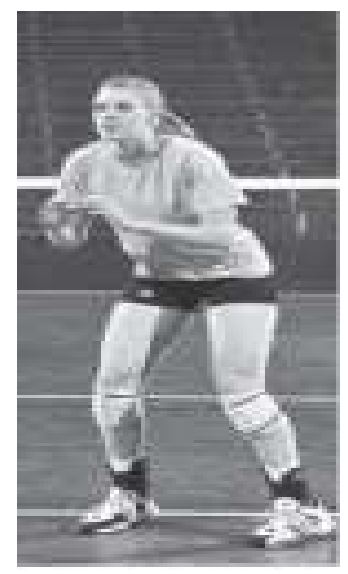

Gambar 3. Sikap Persiapan Saat Melakukan Passing Atas Sumber: Waite Pete., Aggresive Volleyball, Dictate the Pace, Determine Outcome (USA:Human Kinetics, 2009), h. 51. 


\section{b. Sikap Perkenaan Bola}

Tahapan dalam teknik passing atas berikutnya yakni tahapan sikap ketika perkenaan dengan bola. Perkenaan bola pada jari adalah di ruas pertama dan kedua, terutama pada ruas pertama dan kedua jari tengah, jari telunjuk dan ruas pertama dan ibu jari. Pada saat ibu jari disentuhkan pada bola maka jari-jari agak ditegangkan sedikit dan pada saat itu pula diikuti dengan gerakan pergelangan tangan, lengan ke arah depan atas agak eksplosif.

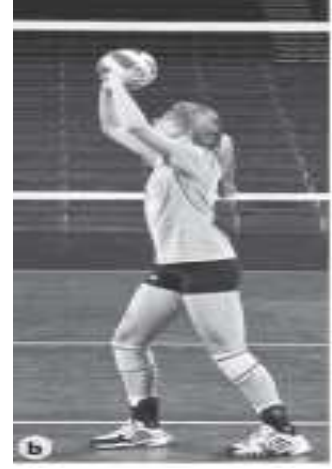

Gambar 4. Sikap Perkenaan Saat Melakukan Passing Atas Sumber: Waite Pete., Aggresive Volleyball, Dictate the Pace, Determine Outcome (USA:Human Kinetics, 2009), h. 51.

\section{c. Sikap Akhir}

Subroto dan Yudiana (2010:48) menyatakan bahwa "sikap akhir atau gerak lanjutan yakni dilakukan dengan meluruskan kedua lengan ke depan atas dan lutut sebagai gerak lanjutan diikuti dengan memindahkan berat badan ke depan dan segera kembali ke posisi normal." Dalam melakukan gerakan teknik passing atas, gerakan tangan, pergelangan, lengan dan kaki adalah satu gerakan rangkaian yang tidak dapat dipisahkan dan pandangan pemain harus pada bola.

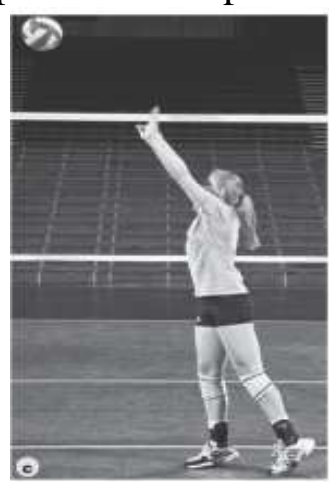

Gambar 5. Sikap Perkenaan Saat Melakukan Passing Atas

Sumber: Waite Pete., Aggresive Volleyball, Dictate the Pace, Determine Outcome (USA:Human Kinetics, 2009), h. 51.

\section{Metodologi Penelitian}

Penelitian pengembangan model passing atas bolavoli ini menggunakan model penelitian dan pengembangan (Research and Development) dari Borg dan Gall (1983:775) yang terdiri dari sepuluh langkah dalam penelitian yakni antara lain:

(1) Research and information collecting (2) Planning (3) Development of the preliminary from of product (4) Preliminary field testing (5) Main product revision (6) Main field test. (7) Operational product revision . 


\section{(8) Operational field testing (9) Final produk (10) Dissemination and implementation.}

Langkah selanjutnya adalah tahapan-tahapan yang dilakukan dalam pengembangan model. Langkah yang dilakukan dalam penelitian riset dan pengembangan model ini melalui tahapan-tahapan sebagai berikut:

a. Tahap evaluasi pertama yang dilakukan pada tahap rancangan bentuk model oleh pakar, evaluasi awal merupakan penilaian pertama dari para ahli untuk:

(1) menentukan apakah model sudah sesuai dengan karakteristik siswa sekolah menengah pertama, (2) apakah model latihan yang dikembangkan cocok untuk siswa sekolah menengah pertama sebelum di uji cobakan.

b. Tahapan evaluasi kedua yang dilakukan pada tahapan uji coba kelompok kecil. Pada evaluasi melalui hasil respon siswa terhadap model 1 dalam tahapan ujicoba ini dilakukan oleh siswa atas tentang: (1) model mudah dipelajari, (2) model aman dilakukan, (3) model menarik dilakukan, dan (4) model bermanfaat untuk anak SMP. Hasil respon siswa atas model pengembangan model yang telah dilaksanakan merupakan evaluasi penyempurnaan produk model untuk siswa sekolah menegah pertama sebelum model tersebut di uji lapangan pada kelompok yang heterogen kemampuannya dan lebih besar jumlah siswanya.

c. Tahapan evaluasi akhir yang dilakukan pada tahapan uji lapangan kelompok besar dan heterogen tingkat kemampuannya. Hasil respon siswa atas model sama seperti pertanyaan di tahapan evaluasi sebelumnya yang nantinya sebagai revisi penyempurnaan hasil produk model passing atas bolavoli siswa sekolah menengah pertama dan di implementasikan.

\section{Hasil Penelitian dan Pembahasan}

Berdasarkan hasil uji efektivitas menggunakan uji-t, dari perbedaan hasil keterampilan dasar passing atas bolavoli antara pretest dengan posttest diperoleh harga $t_{O}=4,512$ lebih besar dari harga $t_{t}=1,796$ (pada taraf signifikansi 0,05), maka hipotesis nihil ditolak serta nilai rata-rata pretest $\left(\mathrm{x}_{1}\right)=12.67$ lebih kecil daripada rata-rata posttest $\left(\mathrm{x}_{2}\right)=13.92$. Sehingga dapat disimpulkan bahwa, terdapat perbedaan yang signifikan antara pretest dan posttest hasil kemampuan dasar passing atas bolavoli.

Dari data penelitian, diperoleh harga rata-rata pretest $\left(\mathrm{x}_{1}\right)=12.67$ lebih kecil daripada rata-rata posttest $\left(\mathrm{x}_{2}\right)=13.92$. Dengan demikian dapat dinyatakan bahwa, model passing atas bolavoli untuk anak usia SMP efektif digunakan untuk meningkatkan hasil kemampuan passing atas bolavoli.

\section{Kesimpulan}

Dari hasil uji coba lapangan dan pembahasan hasil penelitian dapat disimpulkan bahwa

1. Berdasarkan hasil evaluasi ahli dan uji coba yang telah dilakukan diperoleh model akhir atau final passing atas bolavoli ini meliputi, (1) Model 1 Ular dan Tikus, (2) Model 2 "Bola Tekan", (3) Model 3 "Double Passing dengan Kaleng", (4) Model 4 "Passing Sasaran", (5) Model 5 "Pantul-Tembok", (6) Model 6 "Rintangan Lumba-Lumba", (7) Model 7 "Bola Keranjang", (8) Model 8 "Passing Berbatas", (9) Model 9 "Rintangan Tali Berumbai", (10) 
Model 10 “Ambil Bola”, (11) Model 11 "Bola dalam Lingkaran”, (12) Model 12 "Bom Kaleng", (13) Model 13 "Saling Umpan", (14) Model 14 "Sasaran Bertingkat", (15) Model 15 "Balap Bola", (16) Model 16 "Bola Bergilir", (17) Model 17 "Three In One, (18) Model 18 "Lari Samping", (19) Model 19 "Sebut Nama Teman", (20) Model 20 "Bom-Boman", (21) Model 21 "Lapangan Berpoint", (22) Model 22 "Voli Kotak", dan (23) Model 23 "Sumur Berbenteng".

2. Berdasarkan hasil uji efektivitas model, terbukti secara empiris bahwa hasil produk yang berupa model passing atas bolavoli untuk usia SMP ini memiliki efektifitas yang sangat baik. Hal itu berdasarkan dari hasil tes keterampilan passing atas bolavoli yang menunjukkan bahwa harga rata-rata hasil posttest lebih besar daripada rata-rata hasil pretest. Sehingga dapat dinyatakan bahwa, model passing atas bolavoli untuk usia SMP ini efektif digunakan untuk meningkatkan hasil passing atas bolavoli untuk usia SMP.

\section{Implikasi}

Berdasarkan kesimpulan hasil penelitian secara menyeluruh menunjukkan bahwa, produk model passing atas bolavoli untuk usia SMP ini ternyata secara keseluruhan layak dan efektif digunakan oleh siswa. Maka, implikasi dari hasil temuan tersebut adalah bahwa passing atas bolavoli ini hendaknya dapat dipertimbangkan oleh para pengajar atau pelatih sebagai panduan alternatif lain atau referensi bagi kegiatan belajar passing atas bolavoli untuk anak usia SMP, karena efektif digunakan untuk meningkatkan hasil kemampuan passing atas bolavoli.

\section{Saran}

\section{Saran Pemanfaatan}

Produk pengembangan ini adalah model passing atas anak usia SMP yang dapat digunakan sebagai rujukan oleh pelatih, guru, atlet maupun siswa. Dalam memanfaatkannya sangat perlu dipertimbangkan situasi, kondisi dan sarana prasarana. Serta peningkatan mutu dari pengajar perlu ditingkatkan untuk mencapai tujuan belajar.

\section{Saran Diseminasi}

Dalam penyebarluasan produk pengembangan ke sasaran yang lebih luas, peneliti memberikan saran sebaiknya sebelum disebarluaskan sebaiknya produk ini disusun kembali menjadi lebih baik, baik itu tentang kemasan tampilan maupun isi dari materi produk yang dikembangkan. Agar model passing atas anak usia SMP ini dapat digunakan, maka sebaiknya dicetak lebih banyak lagi, sehingga nantinya para pengguna dapat mengetahui dan mampu menguasai passing atas dengan baik.

\section{Saran Pengembangan Lebih Lanjut}

Dalam mengembangkan penelitian ini ke arah lebih lanjut, peneliti mempunyai beberapa saran seperti pada subyek penelitian sebaiknya dilakukan pada subyek yang lebih luas, baik itu di sekolah menengah pertama maupun di klub-klub bolavoli selain yang digunakan sebagai kelompok ujicoba. Hasil pengembangan model passing atas anak usia SMP ini dapat disebarluaskan ke sekolah menengah pertama maupun klub bolavoli. 


\section{DAFTAR RUJUKAN}

Ahmadi, Nuril. Panduan Olahraga Bolavoli. Surakarta: Era Pustaka Utama, 2007. Atmasubrata, Ginanjar. Serba Tahu Dunia Olahraga. Surabaya: Dafa Publishing, 2012.

Borg, W.R dan Gall, M.D. 1983. Educational Research An Introduction. New York:Longman, 1983.

Beutelstahl, Dieter. Belajar Bermain Bola Volley. Bandung: Pionir jaya, 2008.

Katrin, Bart \& Richard Heuchert., Learning Volleyball. Germany:Meyer And Meyer Sport, 2007.

Kus, Sally. Choaching Volleyball Successfully. USA: Human Kinetics, 2004.

Papageorgiou, Athanasious. Volleyball a Handbook For Choach and Player. USA: Meyer and Meyer Sport, 2002.

Pete, Waite. Aggresive Volleyball, Dictate The Pace, Determine Outcome. USA:Human Kinetics, 2009.

Semiawan, Conny. Catatan Kecil Tentang Penelitian dan Pengembangan Ilmu Pengetahuan. Jakarta: Kencana Prenada Media Group, 2007.

Setyosari, Punaji. Metode Penelitian Pendidikan dan Pengembangan. Jakarta: Prenada Media Group, 2013.

Subroto, Toto dan Yunyun Yudiana. Modul Permainan Bolavoli. Bandung: Universitas Pendidikan Indonesia, 2010.

Sugiyanto, dkk. Perkembangan Dan Belajar Motorik, Jakarta: Mendikbud, 2007.

Sugiyono. Metode Penelitian Kuantitatif, Kualitatif dan $R$ \& D. Bandung: Alfabeta, 2013.

Sugiyono. Motode Penelitian Pendidikan, pendekatan kuantitatif, kualitatif dan $R \& D$. Bandung: Alfabeta, 2008.

Sukmadinata, Nana Syaodih. Metode Penelitian Pendidikan. Bandung:Rosda, 2012.

Viera, Barbara L dan Bonnie Jill Fergusson. Bolavoli Tingkat Pemula. Jakarta: Raja Grafindo Persada, 2000.

---------. Volleyball Step to Success Second Edition (Canada:Human Kinetics, 2010), h. 49.

Winarno, M.E. Metodologi Penelitian Dalam Pendidikan Jasmani. Malang: Media Cakrawala Utama Press, 2011. 